\title{
Back to the roots:
}

\section{Diversity and community composition of root-associated fungi explored by high throughput sequencing}

\author{
BY \\ RAKEL BLAALID \\ DISSERTATION PRESENTED FOR THE DEGREE OF \\ PHILOSOPHIAE DOCTOR \\ 2012

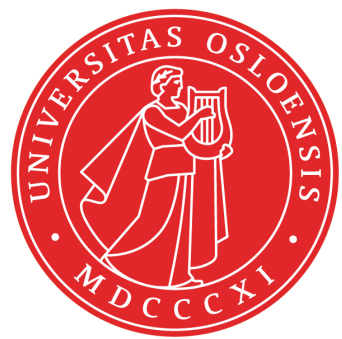

University of Oslo

Faculty of Mathematics and Natural Sciences

Department of Biology

Microbial Evolution Research Group 
(C) Rakel Blaalid, 2012

Series of dissertations submitted to the

Faculty of Mathematics and Natural Sciences, University of Oslo No. 1219

ISSN 1501-7710

All rights reserved. No part of this publication may be reproduced or transmitted, in any form or by any means, without permission.

Cover: Inger Sandved Anfinsen.

Printed in Norway: AIT Oslo AS.

Produced in co-operation with Akademika publishing. The thesis is produced by Unipub merely in connection with the thesis defence. Kindly direct all inquiries regarding the thesis to the copyright holder or the unit which grants the doctorate. 


\section{Table of Contents}

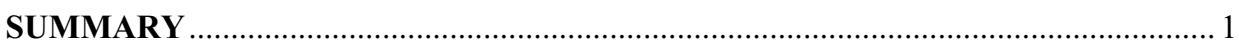

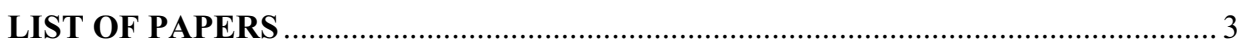

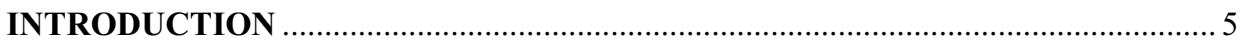

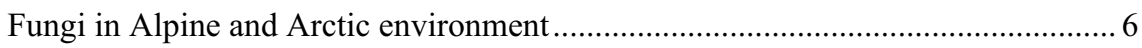

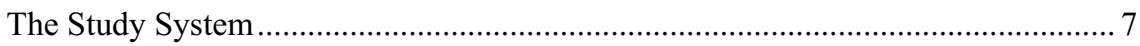

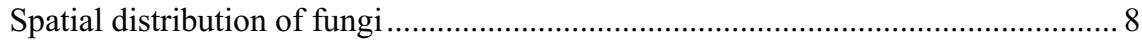

High throughput sequencing of fungal communities ......................................... 9

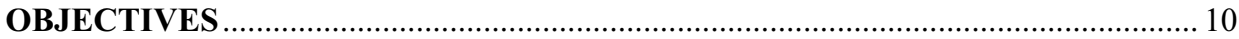

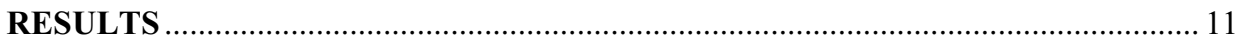

Paper I. ITS1 versus ITS2 as DNA metabarcodes for fungi ................................ 11

Paper II. Fungal community structure at small spatial scales .............................. 11

Paper III. Primary succession in alpine areas ..................................................... 11

Paper IV. Primary succession in arctic versus alpine glacier areas ....................... 12

Paper V. Biogeography of fungal communities in the Arctic ............................... 12

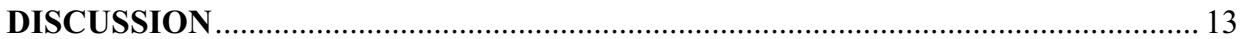

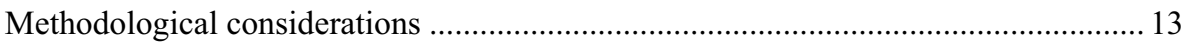

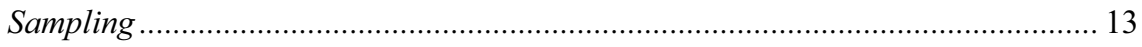

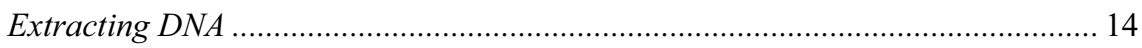

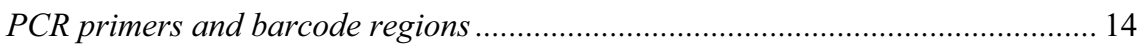

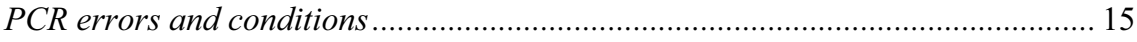

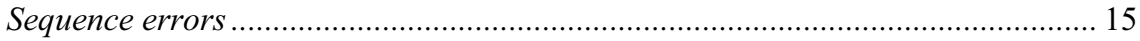

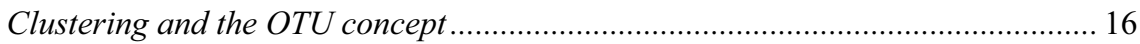

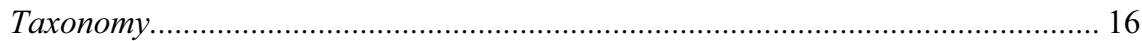

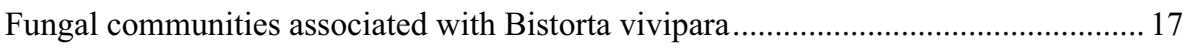

Taxonomy of the root-associated fungal communities ........................................ 17

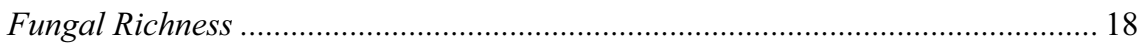

Spatial structure of the fungal communities ......................................................... 19

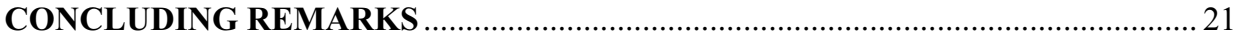


FUTURE PERSPECTIVES

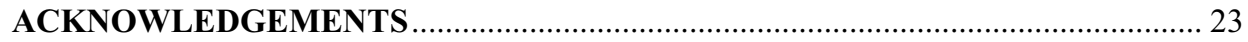

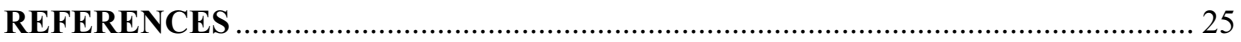

PAPER I

PAPER II

PAPER III

PAPER IV

PAPER V 


\section{Summary}

Interactions between plant roots and fungi are well known from most terrestrial ecosystems. Mycorrhizal association is the most prominent plant-fungi interaction, where the fungal partners increase the water and nutrient uptake of their host plants. This symbiosis might be especially important in marginal habitats like arctic and alpine environments. The structure, diversity and spatial patterns of the root-associated fungal communities are to a large extent unknown due to previous methodological limitations. The main objective in this thesis was to implement high throughput DNA sequencing to assess the community structure, richness and spatial distribution of root-associated fungal communities in arctic and alpine environments. We focused on one host plant species, namely the ectomycorrhizal herb Bistorta vivipara. Its small and condensed root system enabled us to analyze the entire fungal assemblages associated with individual root systems, using 454 pyrosequencing of ITS1 and/or ITS2 amplicons. All the five studies included in this thesis revealed that the most prominent fungal groups were well-known ectomycorrhizal fungi such as Agaricales, Sebacinales and Thelephorales. Furthermore, ascomycete fungi of the order Helotiales were also recovered frequently across all root systems. Although a high patchiness in fungal community composition generally was observed, some systematic compositional changes along gradients were observed. In a $2 \times 2$ $\mathrm{m}^{2}$ local scale study, a spatial autocorrelation was observed at small scales $(<0.34 \mathrm{~m})$. Furthermore, a significant compositional difference was observed between the rootassociated fungal communities and adjacent soil fungal communities. Along two primary succession gradients in arctic and alpine areas, a systematic compositional shift was observed. The fungal richness increased along the chronosequences towards the climax vegetation. In a biogeographic survey, where the root-associated fungi were analyzed across Svalbard, a compositional shift was observed that was associated with the latitudinal gradient. Moreover, the fungal richness increased westwards in the more climatic favorable habitats. Overall, the different studies indicate that stochastic processes, possibly related to aerial spore dispersal, are important during fungal community establishment. The conducted studies exemplify that high throughput sequencing is a powerful approach for analyzing complex microbial communities. 


\section{List of Papers}

The thesis is based on the following five papers, which will be referred to in the text by their Roman numerals:

I. Blaalid R, Kumar S, Nilsson RH, Abarenkov K, Xiaoli Z, Kirk P, Kauserud H. 2012. ITS1 versus ITS2 as DNA metabarcodes for fungi. Accepted in Molecular Ecology Resources.

II. Blaalid R, Heegaard E, Halvorsen R, Kauserud H. 2012. Community structure of plant root associated fungi at small spatial scales in an alpine ecosystem. Submitted to MicrobiologyOpen

III. Blaalid R, Carlsen T, Kumar S, Halvorsen R, Ugland KI, Fontana G, Kauserud H. 2012. Changes in the root-associated fungal communities along a primary succession gradient analysed by 454 pyrosequencing. Molecular Ecology, 21, 1897-1908.

IV. Eidesen PB, Blaalid R, Carlsen T, Kauserud H. 2012. Does latitude make a difference? Comparison of primary succession of root associated fungi along chronosequences in arctic versus alpine glacier forelands. (Manuscript)

V. Blaalid R, Carlsen T, Eidesen PB, Halvorsen R, Høiland K, Kauserud H. 2012. Biogeography of root associated fungal communities in the Arctic Archipelago Svalbard, Norway. (Manuscript). 


\section{Introduction}

There is little consensus about how many fungal species that exist on earth, but the wellknown estimate of 1.5 mill species (Hawksworth, 1991) seems to be a dramatic underestimate (Blackwell, 2011; Bass \& Richards, 2011). Fungi are present in all biomes and most ecosystems, here playing important functional roles as saprotrophs, parasites and symbionts. Large proportions of all fungi are associated with plants (Hawksworth, 1991) and have plants as their main carbon source. Plants and fungi have a long history together and have co-evolved for some 450 million years since plants established on land (Smith \& Read, 2008). Fungi interact with plants in various ways, having both negative and positive effects on their host plants. However, while there are many assumptions about plant-fungi interactions we have still very little knowledge about how most fungi interact with plants. Mycorrhiza is probably the most prominent interaction between plants and fungi and is a symbiosis of uttermost importance in most terrestrial ecosystems. It is assumed that both partners benefit from this relationship; the fungus by gaining photosynthesis products from their host and the plants by having an increased uptake of nutrients and water (Smith \& Read, 2008). However, in an ideal 'plant world' with no nutrient and water limitation, competition pressure, or plant predation, plants would probably not enter into this symbiosis. The fungus on the other hand needs the plant regardless as carbon source. Mycorrhizal symbiosis is divided into different types, based on which plant and fungal partner being involved. Arbuscular mycorrhiza, formed by the monophyletic group Glomeromycota (AM), is found in nearly all plant families (Wang \& Qiu, 2006; Krüger et al., 2012). Hyphal fungi, forming vesicles and arbuscles very similar to todays Glomeromycetes, have been found in 400 million years old plant fossils (Remy et al., 1994). Hence, this group may have played an important role during plants establishment on land (Nicolson, 1975; Smith \& Read, 2008). Ericoid mycorrhiza (ErM), found among Ericaceous plants, is formed by the ascomycetous group Helotiales. Ectomycorrhiza (ECM) can be formed by diverse phylogenetic groups, including zygomycetes, ascomycetes and, most prominently, basidiomycetes. ECM includes a variety of plant partners across Plantae, usually trees and shrubs. The ECM symbiosis is thought to have arisen simultaneously as the gymnosperm family Pinaceae close to 130 mya (Axelrod, 1986; Trappe, 1987; Smith \& Read, 2008). Today the ECM diversity includes over 6000 
plant species and probably closer to 20,0000 fungal partners. In addition to mycorrhiza, most plants harbor an enormous diversity of fungal endophytes both in above- and belowground parts. Dark septated root endophytes (DSE fungi) have been reported for $>600$ plant species within all habitats, emphasizing their status as important fungal members in the plant rhizosphere (Jumpponen \& Trappe, 1998). Whether DSE fungi enhances host fitness has been debated, and there is seemingly differences between the host responses to these fungi (Jumpponen, 2001). Today, DSE fungi are largely regarded as mycorrhiza-like fungi (Jumpponen, 2001; Newsham et al., 2009; Newsham, 2011) increasing the biomass of their hosts with 52-138\% (Newsham, 2011).

\section{Fungi in Alpine and Arctic environments}

Alpine and Arctic environments are cold ecosystems with low nutrient availability, unstable conditions and short growth seasons. In most areas, less than ten plant species comprise more than 90\% biomass (Chapin \& Körner, 1995), and most of them form mutualistic relationships with fungi (Smith \& Read, 2008). Many potential ECM or ErM host plants are co-occurring within both arctic and alpine systems (Gardes \& Dahlberg, 1996). Still, nearly no host specificity has been observed for either ECM fungi (Gardes \& Dahlberg, 1996) or ErM fungi (Walker et al., 2005). A high degree of heterogeneity and richness of ECM fungi within arctic and alpine areas has been observed (Gardes \& Dahlberg, 1996; Kjøller et al., 2010; Bjorbækmo et al., 2012) emphasizing their importance for plant survival in alpine and arctic ecosystems (Gardes \& Dahlberg, 1996; Haselwandter \& Read, 1987; Nara, 2006). AM is rare in high altitudes (Haselwandter \& Read, 1982; Haselwandter et al., 1983) and arctic environments (Väre et al., 1992), while ECM and ErM are widespread. Typical ECM forming fungal genera in alpine/arctic environments are Cortinarius, Inocybe, Laccaria, Tomentella and Hebeloma (Väre et al., 1992; Jumpponen et al., 2002; Bjorbækmo et al., 2010; Geml et al., 2012). Although no fungal genera are shown to be exclusive to alpine and arctic environments, adaptations towards living within these harsh environments have been observed (Tibbett et al. 1998,1999).

DSE fungi (defined as anamorphic Helotiales; Smith \& Read, 2008) have shown to be highly abundant in both arctic (Väre et al., 1992, Bledsoe et al. 1990: Newsham et al., 2009; Bjorbækmo et al., 2010) and alpine (Haselwandter \& Read, 1980, 1982; Currah \& Van Dyk, 1986; Jumpponen \& Trappe, 1998; Schmidt et al. 2008) environments. 
Although, DSE fungi are common in all biomes, they may fill a specific niche here, due to the general absence of glomeromycetes. Their functional status has been proposed to be pathogenic (Wilcox \& Wang, 1987; Stoyke \& Currah, 1993) and mutualistic (Haselwandter \& Read, 1982; Jumpponen et al., 1998), dependent on host-fungus combinations (Wilcox \& Wang, 1987). Based on these observations, DSE fungi might be considered partly mycorrhizal, as host responses to mycorrhizal fungi are considered to be a continuum ranging from parasitism to mutualistism (Jumpponen, 2001; Mandyam \& Jumpponen, 2005).

Recent studies of fungal communities within arctic and alpine areas have mainly focused on fungal community responses to gradients (Jumpponen et al., 2002; Jumpponen, 2004; Cazares et al., 2005; Nara \& Hogetsu, 2004; Nara, 2006; Bjorbækmo et al., 2010) and colonization of fungi in remote areas (Jumpponen et al., 1999; Geml et al., 2012). Given the rising concern of climate change, particularly in arctic and alpine environments, enumerating the fungal diversity present and determining responses of these communities to abiotic change is of urgent importance.

\section{The study system}

Bistorta vivipara (Figure 1.) is a perennial herb in the family Polygonaceae common in alpine and arctic environments. This species has an important ecosystem function within these environments, as a common part of the diet of reindeer and ptarmigan (Moss \& Parkinson, 1975; Pardoe, 1995). ECM associations on the roots of B. vivipara were first described by Hesselmann (1900), and have later been confirmed by numerous studies (Read \& Haselwandter, 1981; Lesica \& Antibus, 1986; Väre et al., 1992; Eriksen et al., 2002; Massicotte et al., 1998; Mühlmann et al., 2008). The distributional range of $B$. vivipara is circumpolar, and in alpine and arctic environments it is a very common plant community member, here often growing together with plants such as Salix spp., Dryas octopetala or Betula nana. In an evolutionary time span B. vivipara might be relatively young ECM plant compared to e.g. Salix spp., D. octopetala and B. nana, as other members of Polygonaceae rarely form ECM. Hence, a host switch of the ECM fungi from co-existing ECM forming plants might have happened. 


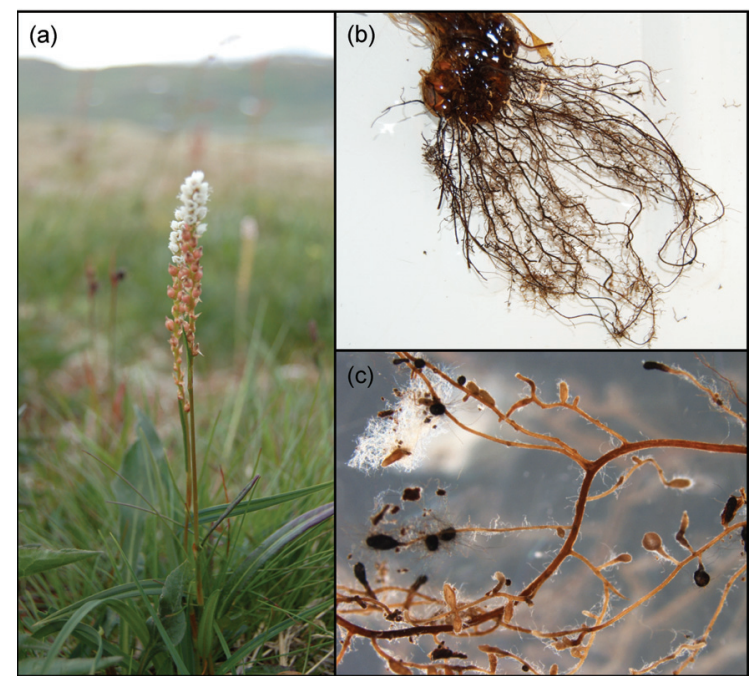

Figure 1. Bistorta

vivipara and its roots,

(a) the above ground

part of the plant

including the

inflorescence (b) washed

root system and (c)

magnified picture of the

roots indicating typical

ECM structures.

\section{Spatial distribution of fungi}

According to Wolfe et al. (2009) and Pickles et al. (2009), the importance of spatial scales has largely been overlooked by fungal ecologists. Often spatial scales are defined to be local, landscape, or regional (Wolfe et al., 2009). Different factors govern the richness and structure of fungal communities at various scales. At a local scale, intermediate disturbance trough root disruption, nutrient availability and soil properties are important (Bruns, 1995). At landscape scale, substrate availability has been proposed as a driving factor (Burrows \& Pfleger 2002; Lilleskov et al., 2004; Wolfe et al., 2009). At regional scales, various climatic drivers might set limits for species occurrences and co-existence (Wollan et al., 2008).

Fungal community responses to gradients (Tedersoo et al., 2003; Green et al., 2006; Toljander et al., 2006) indicate spatial dependency, hence fungal communities are spatially structured and a deterministic model opposed to a stochastic model of fungal distribution is likely. However, numerous studies have indicated that fungi in general are patchily distributed (Horton \& Bruns, 2001; Jumpponen et al., 2002; Lilleskov et al., 2004; Stukenbrock \& Rosendahl, 2005; Taylor et al., 2010) at both local and landscape scale. Patchiness is usually associated with lack of spatial structure. According to Wolfe et al. (2009) spatial patterns are easier to observe at regional scale due to the high degree of heterogeneity and local diversity within local/landscape scales. This heterogeneity potentially blurs out spatial patterns, and fungal communities are therefore often 
considered to lack structure at smaller spatial scales (e.g. landscape/local scales).

Historically, community ecology studies have ignored spatial scales (Pickles et al., 2009;

Wolfe et al., 2009) and as such, inferences of spatial dependency remain largely

unresolved, presenting future challenges for fungal ecology.

\section{High throughput sequencing of fungal communities}

Molecular tools such as PCR and Sanger sequencing revolutionized fungal research from the early 90s (Horton \& Bruns, 2001). During the last 20 years, these techniques have been used in fungal taxonomy as well as fungal ecology, for identification of new species and understanding complex ecological relationships. However, these methods are limiting fungal ecological studies because they are time consuming and expensive, typically capturing only the most abundant taxa, normally leaving the rare ones unaccounted for (Taylor, 2002). This proposes a dilemma, as most fungal communities seem to be composed of a few abundant- and many rare species (Taylor, 2002).

During the last five years, new generations of DNA sequencing techniques, so called high throughput sequencing (HTS), have been developed and are now widely used in fungal ecology research (Buée et al., 2008, Öpik et al., 2009; Jumpponen \& Jones, 2009; Tedersoo et al., 2010; Kauserud et al., 2012). The most promising new method is the 454-pyrosequencing techniques, where thousands of DNA sequences are generated in parallel, each from different single DNA molecule templates (Margulies et al., 2005). Sequencing single DNA molecules within a mixture of molecules, allows for the identification of both the dominant taxa as well as rare taxa in environmental samples. The new sequencing techniques now make us able to analyze fungal communities both to greater detail and more extensively. Hundreds of environmental samples can now be processed in parallel and deep sequence coverage can be obtained from each sample. However, the new sequencing techniques have led to new challenges; until recently, the main focus of most researchers was to generate sequence data, now the main challenge is to handle, process and store huge sequence datasets. 


\section{Objectives}

The overarching aim of this $\mathrm{PhD}$-thesis was to assess the root-associated fungal richness and community structure at different spatial scales using high throughput sequencing (HTS).

More specific aims were to:

- Explore the usability of high throughput sequencing to analyse fungal communities $(\mathrm{I}-\mathrm{V})$

- Evaluate the usability of ITS1 versus ITS2 as DNA metabarcodes for fungi (I)

- Reveal the diversity and spatial structure of root associated fungal communities at different spatial scales in alpine and arctic environments (II-V)

- Investigate the structural differences of fungal communities found within plant roots versus adjacent soil (II)

- Assess the fungal structure and diversity along primary successional gradients in alpine and arctic environments (III, IV) 


\section{Results}

\section{Paper I. ITS1 versus ITS2 as DNA metabarcodes for fungi}

Within paper I, we evaluate the usability of ITS1 versus ITS2 as a DNA metabarcoding marker for fungi. ClustEx revealed that a 97\% similarity cut-off represent a reasonable threshold for estimating the number of known species in the datasets for both ITS1 and ITS2, although no single threshold value worked well for all fungi at the same time. We found that the Operational Taxonomic Unit (OTU) concept is not easily translated into the level of species because many species are distributed on several clusters. 454 pyrosequencing data revealed a high similarity between the two datasets when it comes to taxonomic coverage, indicating that ITS1 and ITS2 to a large extent yield similar results when used as DNA metabarcodes for fungi.

\section{Paper II. Fungal community structure at small spatial scales}

In paper II we assessed the community structure and spatial distribution of fungi in a $2 \times 2$ $\mathrm{m}$ plot in an alpine area in Norway, using the ITS2 marker. Parallel analyses were made of fungi associated with $B$. vivipara roots and adjacent soil. Fungal diversity was higher in soil compared to roots, and the fungal community composition differed considerably. Fungi with taxonomic affinity to Sebacinales and Helotiales were more frequent in plant roots while fungi belonging to Tremellales and Mortierellales were relatively more frequent in soil. Only at a fine scale $(<34 \mathrm{~cm})$ we observed a spatial autocorrelation in the fungal community composition in plant roots. The high degree of patchiness and limited spatial autocorrelation indicates that random colonization events from aerial spores or soil erosion are likely the most important factors structuring the studied alpine fungal communities.

\section{Paper III. Primary succession in alpine areas}

In paper III our main objective was to assess the degree of variation in fungal richness and community composition along a primary succession gradient using the ITS1 as marker. Already in the first stage of succession a high fungal diversity was present in the $B$. vivipara root systems and the total fungal richness increased significantly along the gradient towards climax vegetation. The high degree of patchiness in distribution of fungal 
OTUs across root systems indicated that stochastic processes to a large extent structure the fungal communities. However, time since deglaciation had impact on the fungal community structure, as a systematic shift in the community composition was observed along the chronosequence.

\section{Paper IV. Primary succession in arctic versus alpine glacier forelands}

In paper IV we compared a primary succession gradient in the Arctic (Svalbard) to the one studied in paper III. Both gradients showed high fungal diversity in early successional stages, and high patchiness in distribution of fungal OTUs both within root systems and among deglaciations stages. Time since deglaciation affected the fungal community along both gradients, but the systematic shift in species composition ( $\beta$-diversity) was stronger at the arctic site. For example, Thelephorales, which was abundant in all stages in the alpine site, was missing from the youngest arctic stage. As in the alpine site, the $\alpha$-diversity clearly peaked in the old, stabilized vegetation in the arctic site. With time, the composition of root-associated fungal communities in the more marginal arctic habitat seems to resemble the more climatic favorable alpine areas.

\section{Paper V. Biogeography of fungal communities in the Arctic}

In paper $\mathrm{V}$ we aimed at answering how the ECM fungal community structure and richness of $B$. vivipara vary at a larger biogeographic scale (Svalbard archipelago) using ITS1 as DNA metabarcoding marker. Roots of B. vivipara were sampled across Spitsbergen and Edgeøya, totaling 185 samples from 37 localities. Basidiomycetous groups including Agaricales, Thelephorales and Sebacinales were the most dominating groups. The diversity of the Svalbard mycoflora indicates weak patterns of biogeographical distribution along a north/south gradient. Fungal species richness was higher within western parts of Svalbard although species accumulation curves indicated insufficient sampling. We found most of the fungal diversity to be patchily distributed, indicating importance of random colonization events from aerial spores or soil erosion. 


\section{Discussion}

The included studies within this thesis (I-V) indicate the large potential of HTS techniques for analyses of structure and diversity of fungal communities. However, there are numerous problems associated with the new techniques. These are discussed below followed by a discussion of the biological findings.

\section{Methodological considerations}

Sampling

In Fig. 2, an overview is provided of the localities where B. vivipara root systems and soil samples were collected. Three of the studies were conducted in alpine environments at Finse, central Norway (I, II and III), one study at the Arctic Archipelago Svalbard (V), and one study is comparing data from Finse and one locality (Ny-Ålesund) at Svalbard (IV). In all studies entire root systems of B. vivipara were collected. The small, condensed root system (Fig. 2) allows us to study the entire fungal community associated with each plant (Kauserud et al., 2012) opposed to only parts of the roots systems (Tedersoo et al., 2003; Tedersoo et al., 2006; Tedersoo et al., 2009). In this way, sampling bias may to a higher extent be avoided. Sampling strategies do affect how we perceive root associated fungal communities (Taylor, 2002), and in root tip based studies there is seemingly a close relationship between numbers of sampled root tips and observed species (Taylor, 2002).

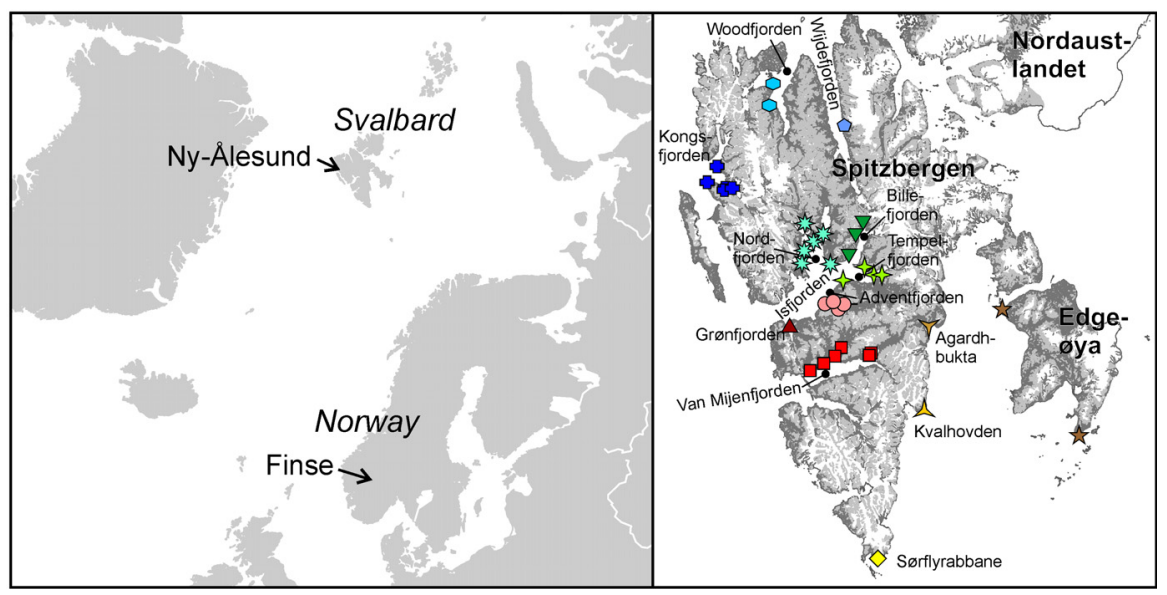


Figure 2. Locality map, indicating the sampling areas for studies I-III, IV and V. In total 410 plant roots and 64 soil samples were included within this thesis.

Replication is a fundamental issue in ecological studies but largely overlooked by most microbiologists (Prosser, 2010). In the studies included in this thesis a high number of samples and replicates are generally included, enabling us to perform rigorously statistical tests for compositional changes and diversity trends.

\section{Extracting DNA}

In all studies, DNA from plant roots was isolated using CTAB extraction (Murray \& Thompson, 1980; Gardes \& Bruns, 1993), while DNA from soil samples was extracted using a MO BIO soil isolation kit (I-II). Extraction method is known to affect the detected fungal community profile (Tedersoo et al., 2010). Studies of bacterial communities have conflicting conclusions about the suitability of the CTAB method (Leuko et al., 2008; Mitchell \& Takacs-Vesbach, 2008). Because of the content of silt and clay within the soil samples, a specific soil isolation kit was used for DNA extraction of the soil samples (I-II). Based on current knowledge I would argue that the CTAB method is appropriate to use for extracting fungal DNA from plant root systems.

\section{PCR primers and barcode region}

The ITS marker is an obvious choice for the analyses of fungal diversity and communities, as it has functioned as the 'unofficial DNA barcode region' for fungi for almost 20 years (Seifert, 2009; Bellemain et al., 2010) and is now accepted as the official barcode of fungi (Schoch et al., 2012). Because of its popularity as a marker in phylogenetics at low taxonomic level, a high number of reference sequences are available in the ISDN databases, as well as in more focused DNA barcoding databases such as UNITE (Abarenkov et al., 2010). The ITS region consists of three subparts; ITS1, the conserved 5.8S and ITS2, and in this thesis, both ITS1 (I+III-V) and ITS2 (I-II) have been used as DNA metabarcoding markers. Because most of the current HTS methods can only generate short $(<500 \mathrm{bp}$ ) reads, i.e. not covering the entire ITS region, decisions whether ITS1 or ITS2 is more suitable as DNA metabarcoding marker is important. A recent study by Mello et al. (2012) found taxonomical differences in the fungal community when analyzing ITS1 and ITS2 in parallel. These observed discrepancies may be attributed to difference in variability within the two sub regions, ITS1 being in general more variable 
compared to ITS2 (Nilsson et al., 2008). There are also more ITS2 sequences available for comparison in the ISDN databases (Nilsson et al., 2008), which may make taxonomical inference easier for the ITS2 region compared to the ITS1 region. Also, the ITS1 primers have shown to be biased towards basidiomycetes whereas ITS2 primers were biased toward ascomycetes (Bellemain et al., 2010).

We demonstrate that choice of region between ITS1 and ITS2 doesn't necessarily affect conclusions in community level ecology as the observed differences between the markers were relatively small, and similar structural patterns were obtained across markers (I).

\section{PCR errors and conditions}

PCR errors are known to occur due to non-perfect polymerase activity and switching of templates during polymerase activity within mixed templates, the latter known as chimeric sequences (Wintzingerode et al., 1997). These chimeras are largely associated with conserved regions, which we have avoided by either working with ITS1 or ITS2, not including the conserved 5.8S region across all studies (I-V). Gonzales et al. (2012) found that low abundant taxa are under-represented due to PCR biases. In fact, compositional changes within mixed templates during PCR have been proved in several studies (Amend et al., 2010; Avis et al., 2010; Engelbrektson et al., 2010). We have refrained from using read abundance data throughout all studies $(\mathbf{I}-\mathbf{V})$ to account for potential PCR introduced biases.

\section{Sequencing errors}

DNA fragments may switch tags during laboratory setup (van Orsouw et al., 2007; Carlsen et al., 2012), most likely prior to the emulsion PCR. If not controlled for, this will cause numerous false positives in downstream analyses. We have tagged the amplicons in both ends before pyrosequencing, to control for potential tag switching across all studies (I-V). These tag switches presents themselves as low frequency OTUs within other samples. To account for these switches, low frequency OTUs ( $<5$ reads) has been omitted from downstream analyses per individual sample in some studies (I, II, V).

Although the 454-methods have improved regarding error rates (Huse et al., 2007), low quality reads are still present, some of them probably due to sequenced PCR errors (Balzer et al., 2011). However, miscounted homopolymers (Kunin et al., 2010) during the 
454-sequencing step have been shown to overestimate diversity. We have accounted for this by collapsing all homopolymers $>6$ across our studies (I-V). To avoid including potential PCR errors and sequencing errors as true diversity, low quality reads have been removed from further downstream analyses (I-V) as recommended by Huse et al. (2007), Quince et al. (2009) and Tedersoo et al. (2010).

\section{Clustering and the OTU concept}

Clustering of sequences into Operational taxonomic units (OTUs) as crude approximation of species proposes many challenges. The terms OTU has been widely adopted and is a preferred entity measure when working with molecular ecology of fungi because an OTU is merely a sequence similarity based surrogate for a species (Sharpton et al., 2011). But how well do the OTUs represent true species? Low sequence coverage will yield more OTUs, and a threshold of $50 \%$ sequence coverage is observed as a minimum requirement to avoid this effect (Kumar et al., 2011). Required sequence similarity is much more debated. The " $3 \%$ golden rule" of sequence dissimilarity to demarcate distinct species has been used in many studies (O'Brien et al. 2005; Morris et al. 2008; Ryberg et al. 2008; Walker et al. 2008; Bjorbækmo et al. 2010; Tedersoo et al. 2010) although plenty of data show that many lineages of the fungal kingdom differ in terms of distance among species (Nilsson et al. 2008; Gazis et al. 2011). Choice of clustering algorithm and overly stringent parameter choice may influence the number of OTUs (Huse et al., 2010; White et al., 2010). In study I, we observed that species (i.e. Latin binomials in the reference sequence datasets analyzed) often were split into several clusters and that many clusters included multiple species. New clustering algorithms, not primarily based on sequence similarity, may offer a solution to avoid multispecies clusters (Pommier et al. 2009; Zinger et al. 2009; Powell et al. 2011).

\section{Taxonomy}

Only a small fraction of the fungal diversity is present in ISDN databases, meaning that only a small fraction of the detected OTUs within HTS studies can be matched to annotated sequences (Nilsson et al., 2009; Hibbett et al., 2009). The approximate number of newly described taxa per year (1223; Hibbett et al., 2009) are in contrast to the millions of sequences generated by HTS methods, indicating that a solution to this problem does not lie within near future. Ecologists not taxonomists are therefore currently discovering 
new fungal taxa, however, the term OTU is far from satisfactory to work with, as it is difficult to make ecological inferences. To add insult to injury to this taxonomical conundrum, many errors are present in sequence reference databases, especially in the uncurated INSD databases (e.g. GenBank; Nilsson et al., 2006).

The OTU concept is based on sequence similarity within a cluster of sequences. But are clusters true representative of species? Clustering sequences with known taxonomic affiliation have indicated that the sequence rich clusters often contains several biological species (I). In addition to this, studies have indicated that within many fungal lineages, the used marker (ITS) is often not able to separate between closely related taxa and closely related species can have identical ITS sequences (Nilsson et al 2008). This advocates for multi-locus approaches when doing HTS studies (Vrålstad, 2011).

Fungal communities associated with Bistorta vivipara Taxonomy of the root-associated fungal communities

Within all studies (I-V) we detected many typical ECM forming taxa such as Agaricales, Thelephorales and Sebacinales. Our consistent findings of Sebacinales and Telephorales as frequent members of the community (I-V) are in contrast with sporocarp studies (Väre $e t$ al., 1992; Gardes \& Dahlberg 1996; Gulden \& Torkelsen, 1996). However, members within these orders have small and inconspicuous fruit bodies, which would explain their previous absence. However, Sebacinales and Thelephorales are frequently detected in studies using molecular tools for taxon identification, especially in arctic and alpine environments (Bjorbækmo et al., 2010, Geml et al., 2012).

Typical dark septated endophytes (DSE) fungi like Phialocephala and Rhizoscyphus were observed within all of our studies (I-V). Many of these OTUs are usually assigned to a low-level taxonomy (order level), which makes it difficult to separate true DSE fungi from other Helotialen groups within our studies (I-V). It is known that DSE fungi are important within arctic and alpine environments (Jumpponen \& Trappe, 1998; Newsham et al., 2009), and they are found widely associated with plants within these areas (Read and Haselwandter, 1981; Väre et al., 1992; Schmidt et al., 2008; Bjorbækmo et al., 2010). Many of the OTUs within our studies (I-V) show affinity to Helotiales, although these OTUs are in many cases only assigned approximately at an order level. Several of these Helotialen fungi may very well represent undescribed DSE fungi, as well as ECM fungi, however more studies are needed to confirm this. 
The composition of the root associated fungal communities was similar at larger spatial scales (Fig. 3; III-V) indicating that the 454-pyrosequencing method is able to capture the representative taxonomic composition across sites. The large fraction of unidentified ascomycetes across all studies emphasizes the importance of further taxonomic work of these groups, including addition of more reference sequences. Unfortunately, the field of taxonomy has over the last three decades been marginalized. In the new HTS era we are totally dependent of good reference sequence data that only trained taxonomist ultimately can provide for most fungal groups.
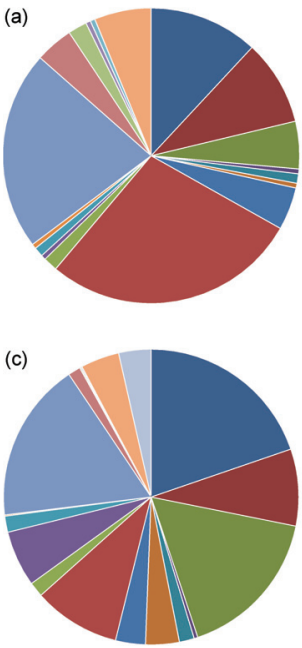

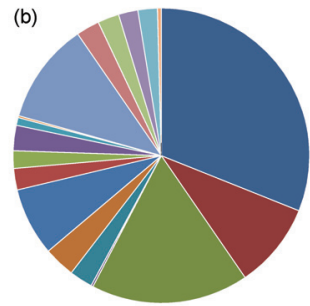

(d)

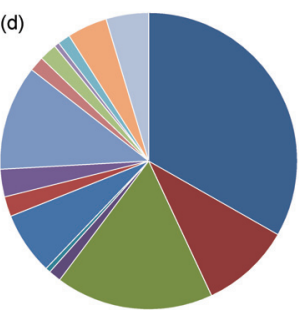

Agaricales

Sebacinales

Thelephorales

Tremellales

Chantarellales

Russulales

Other basidiomycetes

- Helotiales

Chaetothyriales

- Pezizales

Leotiomycetes

Lecanorales

Other ascomycetes

Mortierellales

- Other zygomycetes

Glomeromycota

Chytridiomycota

- Other fungal groups

Fungi (poor match)
Figure 3. Taxonomic

composition within

Bistorta vivipara roots

from (a) the local

community study (II), (b)

alpine primary succession

(III, IV), (c) arctic

biogeography study (V)

(d) arctic primary

succession (IV).

\section{Fungal richness}

Across all studies the fungal species richness was high (I-V) (Fig. 4). Not surprisingly, the fungal richness at local scale (II) was clearly lower compared to the richness found at a biogeographical scale $(\mathbf{V})$ regardless of number of samples, verifying the species-area hypothesis (Arrhenius, 1921). Habitat heterogeneity plays an important role when it comes to fungal species richness (Bruns, 1995). All the large-scale studies (III-V) have close to linear accumulation curves, indicating insufficient sampling. However, the high heterogeneity of the fungal community may be the reason for why a horizontal asymptote will never be reached. If the fungal species are distributed mainly due to stochastic events, that patchy structure is merely a reflection of the fungal community structure. Larger areas share, in general, less species compared to smaller areas. In spite of this, a low degree of spatial autocorrelation was detected even at small spatial scales (II). 


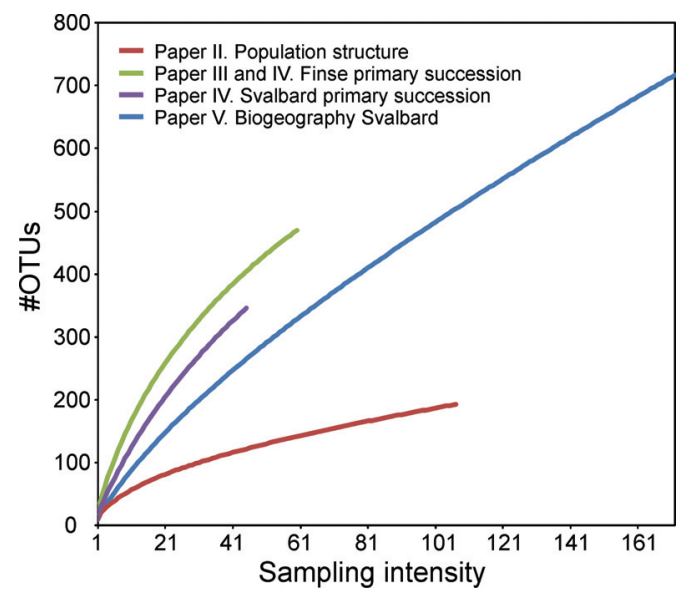

Figure 4. OTU accumulation curves from the local community (II), alpine primary succession (III, IV), arctic primary succession (IV) and arctic biogeography $(\mathbf{V})$.

\section{Spatial structure of the fungal communities}

Species responses to gradients are a central point in all studies dealing with community ecology. Many factors are thought to govern these communities, such as dispersal ability, habitat remoteness, ability to colonize, competition, and predation. Differences between fungal communities found in plant roots and adjacent soil samples indicated that the fungal communities are not only randomly distributed, but habitat specific. We also found structural trends along gradients (III, IV, V) at landscape and regional scale, and along primary succession gradients, favoring a deterministic distribution model, at least for some members within the fungal community.

However, in all studies (II-V), most of the fungi was patchily distributed, indication lack of spatial responses. This means that a stochastic distribution model governs large fractions of the fungal community. We cannot exclude the possibility that we are operating on too coarse scales for detection the spatial dependencies and fungal responses to gradients.

The common denominator across all studies (II-V) is that even though structure was observed, the heterogeneity of the data is very large and a high degree of patchiness was observed even on small scales (II). Many fungal species must be considered rare, thus it is impossible to infer spatial patterns of OTUs occurring in single root systems (I-V). Explanations for these observations may be that most fungi rather co-exists rather that out- 
compete each other due to the niche partition theory (Bruns, 1995). According to this theory, we will observe (1) high fungal richness, (observed across II-V) and (2) low degree of structure (observed across II-V).

The take home message from the studies in this thesis is that there are some widespread and common fungi that respond in a predictable way to known ecological gradients. But the majority of fungi are rare and patchily distributed. Perhaps by looking for structure in our datasets biologists are overlooking the main pattern governing the distribution of most fungi. Which is stochasticity. 


\section{Concluding Remarks}

Although the 454-pyrosequencing technique has proved to be a very powerful approach, there is still considerable room for improvement of the methodology. In addition to methodological challenges, accurate taxonomic assignment is difficult. In many studies using HTS technology, many of the sequences generated do not have good blast matches to any species within reference databases, and therefore are annotated at a higher taxonomic level than what gives ecological information. Throughout all studies included in this thesis, the term OTU has been applied and annotating these with unambiguous species names has been impossible due to the low number of taxonomic reference sequences. How informative are the number of OTUs, and "What's in a name"? I would argue a lot lies within species names! We cannot disregard the importance of naming an organism for further ecological inferences; hence more taxonomical studies across all fungal groups are crucial. 


\section{Future perspectives}

The use of pyrosequencing techniques imposes two major challenges. The first is directly connected to the method it self, the comparison of fungal communities across studies. The inconsistency in data treatment, and different preferential molecular marker among mycological "schools", makes large-scale inferences of fungal communities difficult. The other issue is the lack of taxonomical resolution of the fungal biota. This proposes challenges in accurately characterize the fungal communities found by the 454-method. The need for taxonomic becomes even more prevailent due to this new methods.

Within the near future even more cost efficient methods such as nanopore sequencing may further revolutionize mycological research. The new (third generation) sequencing technologies have the potential to dramatically improve molecular ecology. In the future, the introduction of these techniques will mean that sequencing will not be the limiting factor in studies. However, the main challenges of these new methods will probably be in downstream analyses, including bioinformatics and more importantly biostatistics.

There is a bright future for fungal ecology! 


\section{Acknowledgements}

I would like to acknowledge all the people who have been working with me, helping me and supporting me in various ways during the last four years.

First and most importantly, I express my sincere gratitude to my "academic megalith" and main supervisor, Dr. Håvard Kauserud. His supervision of this project has doubtless been the most significant influence in my academic understanding of the fungal world. His general enthusiasm, team-mentality and pragmatic view on academic life has made these four years great.

I am also grateful to the rest of the supervision team. Thank you, Dr. Tor Carlsen, for listening to my (sometimes endless) complaints and pointing out alternate directions on various projects. Thank you, Professor Rune Halvorsen, for increasing my understanding about biostatistics and for your positivity and availability. Thank you, Professor Klaus Høiland, for helping me understand that fungi are more than just OTUs, and for various fun-facts from the fungal world and beyond. Thank you Dr. Anne Krag Brysting for your positivity and warmth and for the fantastic rimboboller you bake.

I would also like to thank Dr. Pernille Bronken Eidesen, without your help and expertise, the arctic part of this project would not exist and Dr. Einar Heegard for statistical help. I would also like to thank the technical staff at the department of Biology, especially Cecilie Mathiesen, the team at CEES labs and the 454-sequencing team, for lab-assistance and sequencing and Finse research alpine station and UNIS staff for facilitating fieldwork.

To Marie, you will always be my Dimelaena. I would like to thank all members of the fungal group, particularly, Unni Vik, Kristian Skaven Seierstad, Anders Aas, Inger Skrede and Unni Vik, you are my friends as well as my collegues! A huge thanks goes to all the members of MERG for making my time here fantastic, I will miss you! 
To Balder Holm, I thank you for you're support and patience (especially towards the end) during the past four years. I also thank my family and friends for love and support during the PhD-journey.

The University of Oslo is acknowledged for financial support.

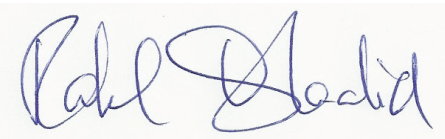

Rakel Blaalid

Oslo 2012 


\section{References}

Abarenkov K, Nilsson RH, Larsson KH, Alexander IC, Eberhardt U, Erland S, Høiland K, Kjøller R, Larsson E, Pennanen T. et al. (2010) The UNITE database for molecular identification of fungi - recent updates and future perspectives. New Phytologist, 186, 281-285.

Amend AS, Seifert KA, Bruns TD. (2010) Quantifying microbial communities with 454 pyrosequencing: does read abundance count? Molecular Ecology, 19, 5555-5565.

Arrhenius O. (1921) Species and Area. Journal of Ecology, 9, 95-99.

Avis PG, Branco S, Tang Y, Mueller GM. (2010) Pooled samples bias fungal community descriptions. Molecular Ecology Resources, 10, 135-141.

Axelrod DI. (1986) Ceoconic history of some western American pines. Annal of the Missouri Botanical Garden, 73, 565-641.

Balzer S, Malde K, Jonassen I. (2011) Systematic exploration of error sources in pyrosequencing flowgram data. Bioinformatics, 27, 304-309.

Bass D, Richards T. (2011) Three reasons to re-evaluate fungal diversity 'on Earth and in the ocean'. Fungal Biology Reviews, 25, 159-164.

Bellemain E, Carlsen T, Brochmann C, Coissac E, Taberlet P, Kauserud H. (2010) ITS as an environmental DNA barcode for fungi: an in silico approach reveals potential PCR biases. BMC Microbiology, 10, 189.

Bjorbækmo, MFM, Carlsen T, Brysting AK, Vrålstad T, Høiland K, Ugland KI, Geml J, Schumacher T, Kauserud H. (2010) High diversity of root associated fungi in both arctic and alpine Dryas octopetala. BMC Plant Biology, 10, 244.

Blackwell M. (2011) The Fungi: 1, 2, 3 ... 5.1 million species? American Journal of Botany, 98, 426-438.

Bledsoe C, Klein P, Bliss LC. (1990) A survey of mycorrhizal plants on Truelove Lowland, Devon Island, N.W.T., Canada. Canadian Journal of Botany, 68, 18481856.

Bruns TD. (1995) Thoughts on the process that maintain local species diversity of ectomycorrhizal fungi. Plant and Soil, 170, 63-73. 
Buée M, Reich M, Murat C, Nilsson RH, Uroz S, Martin F. (2009) 454 Pyrosequencing analyses of forest soils reveal an unexpectedly high fungal diversity. New Phytologist, 184, 449-456.

Burrows RL, Pfleger FL. (2002) Arbuscular mycorrhizal fungi respond to increasing plant diversity. Canadian Journal of Botany, 80, 120-130.

Carlsen T, Aas AB, Lindner D, Vrålstad T, Schumacher T, Kauserud H. (2012) Don’t make a mista(g)ke: Is tag switching an overlooked source of error in amplicon pyrosequencing studies? In review in Fungal Ecology.

Chapin FS, Körner CH. (1995) Patterns, causes, changes, and consequences of biodiversity in arctic and alpine ecosystems. In Arctic and Alpine biodiversity. Eds: Chapin FS, Körner CH. Springer-Verlag Berlin Heidelberg, 313-320.

Cázares E, Trappe JM, Jumpponen A. (2005) Mycorrhizal-plant colonization patterns on a subalpine glacier forefront as a model system of primary succession. Mycorrhiza, 15, 405-416.

Currah RS, Van Dyk M. (1986) A survey of some perennial vascular plant species native to Alberta for occurrence of mycorrhizal fungi. Canadian Field-Naturalist, 100, 330342.

Engelbrektson A, Kunin V, Wrighton KC, Zvenigorodsky N, Chen F, Ochman H, Hugemholtz P. (2010) Experimental factors affecting PCR-based estimates of microbial species richness and evenness. The ISME Journal, 4, 642-647.

Eriksen M, Bjureke KE, Dhillion SS. (2002) Mycorrhizal plants of traditionally managed boreal grasslands in Norway. Mycorrhiza, 12, 117-123.

Gardes M, Bruns TD. (1993) ITS primers with enhanced specificity for basidiomycetesapplication to the identification of mycorrhizae and rusts. Molecular Ecology, 2, 113-118.

Gardes M, Dahlberg A. (1996) Mycorrhizal diversity in arctic and alpine tundra: an open question. New Phytologist, 133, 147-157.

Gazis R, Rhener S, Chaverri P. (2011) Species delimitation in fungal endophyte diversity studies and its implications in ecological and biogeographic inferences. Molecular Ecology, 30, 3001-3013.

Geml J, Timling I, Robinson CH, Lennon N, Nusbaum HC, Brochmann C, Noordeloos ME, Taylor DL. (2012) An Arctic community of symbiotic fungi assembled by long- 
distance disperses: phylogenetic diversity of ectomycorrhizal basidiomycetes in Svalbard based on soil and sporocarp DNA. Journal of Biogeography, 39, 74-88. Gonzales JM, Portillo MC, Belda-Ferre P, Mira A. (2012) Amplification by PCR Artificially Reduces the Proportion of the Rare Biosphere in Microbial Communities. PLoS ONE, 7, e29973.

Green JL, Holmes AJ, Westoby M, Oliver I, Briscoe D, Dangerfield M, Gillings M, Beattie AJ. (2004) Spatial scaling of microbial eukaryote diversity. Nature, 432, 747-750. Gulden G, Torkelsen AE. (1996) Fungi I. Basidiomycota: Agaricales, Aphyllophorales, Exobasdiales, Dacrymycetales and Tremellales. A catalogue of Svalbard plants, fungi, algae and cyanobacteria (ed. by A. Elvebakk and P. Prestrud), pp 173-206. Norsk Polarinstitutt Skrifter 198, Oslo, Norway.

Haselwandter K, Read DJ. (1980) Fungal associations of the roots of dominant and subdominant plants in high-alpine vegetation systems with special reference to mycorrhiza. Oecologia, 45, 57-62.

Haselwandter K, Read DJ. (1982) The significance of root-fungus associations in two Carex species of high alpine communities. Oecologica, 53, 352-354.

Haselwandter K, Hofmann A, Holzmann HP, Read DJ. (1983) Availability of nitrogen and phosphorous in the nival zone of the Alps. Oecologica, 57, 266-269.

Haselwandter K, Read DJ. (1987) Mycorrhizal infection and its possible ecological significance in climactically and nutritionally stressed alpine plant communities. Angewandte Botanik, 61, 107-114.

Hawksworth DL. (1991) The fungal dimension of biodiversity: Magnitude, signifi cance, and conservation. Mycological Research, 95, $641-655$.

Hesselmann H. (1900) Om mycorrhizabildingar hos artiska växter. Bihang till Kongliga Svenska Vetenskaps-Akademiens Handlingar, 26, 1-46.

Hibbett DS, Ohman A, Kirk PM. (2009) Fungal ecology catching fire. New Phytologist, 184, 279-282.

Horton TR, Bruns TD. (2001) The molecular revolution in ectomycorrhizal ecology: peeking into the black-box. Molecular Ecology, 10,1855-1871.

Huse SM, Huber J, Morrison HG, Sogin ML, Welch DBM. (2007) Accuracy and quality of massively parallel DNA pyrosequencing. Genome Biology, R:143. 
Huse SM, Welch DM, Morrison HG, Sogin ML. (2010) Ironing out the wrinkles in the rare biosphere through improved OTU clustering. Environmental Microbiology, 12, 1889-1898.

Jumpponen A, Trappe JM. (1998) Dark septate endophytes: a review of facultative biotrophic root-colonizing fungi. New Phytologist, 140, 295-310.

Jumpponen A, Väre H, Mattson KG, Ohtonen R, Trappe JM. (1999) Characterization of "safe sites" for pioneers in primary succession on recently deglaciated terrain. Journal of Ecology, 87, 98-105.

Jumpponen A. (2001) Dark septate endophytes - are they mycorrhizal? Mycorrhiza, 11, 207-211.

Jumpponen A, Trappe, JM, Cázares E. (2002) Occurrence of ectomycorrhizal fungi on the forefront of retreating Lyman Glacier (Washington, USA) in relation to time since deglaciation. Mycorrhiza, 12, 43-49.

Jumpponen A. (2004) Soil Fungal Communities Underneath Willow Canopies on a Primary Successional Glacier Forefront: rDNA Sequence Results Can Be Affected by Primer Selection and Chimeric Data. Microbial Ecology, 53, 233-246.

Jumpponen A, Jones KL. (2009) Massively parallel 454 sequencing indicates hyperdiverse fungal communities in temperate Quercus macrocarpa phylloshere. New Phytologist, $184,438-448$.

Kauserud H, Kumar S, Brysting AK, Nordén J, Carlsen T. (2012) High consistency between replicate 454 pyrosequencing analyses of ectomycorrhizal plant root samples. Mycorrhiza, 22, 309-315.

Kjøller R, Olsrud M, Michelsen A. (2010) Co-existing ericaceous plant species in a subarctic mire community share fungal root endophytes. Fungal Ecology, 3, 205214.

Krüger M, Krüger C, Walker C, Stockinger H, Schüßler A. (2012) Phylogenetic reference data for systematics and phylotaxonomy of arbuscular mycorrhizal fungi from phylum to species level. New Phytologist, 193, 970-984.

Kumar S, Carlsen T, Mevik B, Enger P, Blaalid R, Shalchian-Tabrizi K, Kauserud H. (2011) CLOTU: an online pipeline for processing and clustering of 454 amplicon reads into OTUs followed by taxonomic annotation. BMC Bioinformatics, 12, 182. 
Kunin V, Engelbrektson A, Ochman H, Hugenholtz P. (2010) Wrinkles in the rare biosphere: pyrosequencing errors can lead to artificial inflation of diversity estimates. Environmental Microbiology, 12, 118-123.

Lesica P, Antibus RK. (1986) Mycorrhizae of alpine fell-field communities on soils derived from crystalline and calcareous parent materials. Canadian Journal of Botany, 64, 1691-1697.

Leuko S, Goh F, Ibáñes-Peral R, Burns BP, Walter MR, Neilan BA. (2008) Lysis efficiency of standard DNA extraction methods for Halococcus spp. in an organic rich environment. Extremophiles, 12, 301-308.

Lilleskov EA, Bruns TD, Horton TR, Taylor DL, Grogan P. (2004) Detection of forest stand-level spatial structure in ectomycorrhizal fungal communities. FEMS Microbiology Ecology, 49, 319-332.

Mandyam K, Jumpponen A. (2005) Seeking the elusive function of the root-colonising dark septate endophytic fungi. Studies in Mycology, 53, 173-189.

Massicotte HB, Melville LH, Peterson RL, Luoma DL. (1998) Anatomical aspects of field ectomycorrhizas on Polygonum viviparum (Polygonaceae) and Kobresia bellardii (Cyperaceae). Mycorrhiza, 7, 287-292.

Margulies M, Egholm M, Altman WE, Attiya S, Bader JS, Bemben LA, Berka J, Braverman MS, Chen Y, Chen Z. et al. (2005) Genome sequencing in microfabricated high-density picolitre reactions. Nature, 437, 376-380.

Mello A, Napoli C, Morin CME, Marceddu G, Bonfante P. (2012) ITS-1 versus ITS-2 pyrosequencing: a comparison of fungal populations in truffle grounds. Mycologia, 103, 1184-1193.

Mitchell KR, Takacs-Vesbach, CD. (2008) A comparison of methods for total community DNA preservation and extraction from various thermal environments Journal of Industrial Microbiology and Biotechnology, 35, 1139-1147.

Moss R, Parkinson, JA. (1975) The digestion of bulbils (Polygonum viviparum L.) and berries (Vaccinium myrtillus L. and Empetrum sp.) by captive ptarmigan (Lagopus mutus). The British Journal of Nutrition, 33, 197-206.

Morris HM, Smith ME, Rizzo DM, Rejmánek M, Bledsoe CS. (2008) Contrasting ectomycorrhizal fungal communities on the roots of co-occurring oaks (Quercus spp.) in a California woodland. New Phytologist, 178, 167-176. 
Mühlmann O, Bacher M, Peintner U. (2008) Polygonum viviparum mycobionts on an alpine primary successional glacier forefront. Mycorrhiza, 18, 87-95.

Murray MG, Thompson, WF. (1980) Rapid isolation of high weight plant DNA. Nucleic Acids Research 8, 4321-4325.

Nara K, Hogetsu T. (2004) Ectomycorrhizal fungi on established shrubs facilitate subsequent seedling establishment of successional plant species. Ecology, 85, 17001707.

Nara K. (2006) Ectomycorrhizal network and seedling establishment during early primary succession. New Phytologist, 169, 169-178.

Newsham KK, Upson R, Read DJ. (2009) Mycorrhizas and dark septate root endophytes in polar regions. Fungal Ecology, 2, 10-20.

Newsham KK. (2011) A meta-analysis of responses to dark septated root endophytes. New Phytologist, 190, 783-793.

Nicolson TH. (1975) Evolution of vesicular-arbuscular mycorrhizas. In Endomycorrhizas. Eds. Sanders FE, Mosse B, Tinker PB, pp 25-34. Academic Press, London, UK.

Nilsson RH, Ryberg M, Kristiansson E, Abarenkov K, Larsson KH, Koljag U. (2006) Taxonomic reliability of DNA sequences in public sequence databases: A fungal perspective. PLOS ONE, 1, e59.

Nilsson RH, Kristiansson E, Ryberg M, Hallenberg N, Larsson KH. (2008) Intraspecific ITS variability in the kingdom Fungi as expressed in the international sequence databases and its implications for molecular species identification. Evolutionary Bioinformatics, 4, 193-201.

Nilsson RH, Ryberg M, Abarenkov K, Sjökvist E, Kristiansson E. (2009) The ITS region as a target for characterization of fungal communities using emerging sequencing technologies. FEMS Microbiology Letters, 296, 97-101.

O’Brien HE, Parrent JL, Jackson JA Moncalvo J, Vilgalys R. (2005) Fungal Community analysis by large-scale sequencing of environmental samples. Applied and Environmental Microbiology, 71, 5544-5550.

Öpik M, Metsis M, Daniell TJ, Zobel M, Moora M. (2009) Large-scale parallel 454 sequencing reveals host ecological group specificity of arbuscular mycorrhizal fungi in a boreonemoral forest. New Phytologist, 184, 424-437.

Pardoe H. (1995) Mountain plants of the British Isles. Number 4, National Museum of Wales. McLays, Cardiff. 
Pickles BJ, Genney D, Anderson IC, Alexander IJ. (2009) Spatial Ecology of

Ectomycorrhizas: Analytical Strategies. In: Mycorrhizas - Functional processes and ecological impact. Eds: Azcón-Aguilar C, Barera JM, Gianinazzi S, GianinazziPearson V. Springer-Verlag, Berlin, Heidelberg pp: 155-165.

Pommier T, Cranbäck B, Lundberg P Hagström Å, Tunlid A. (2009) RAMI: a tool for identification and characterization of phylogenetic clusters in microbial communities. Bioinformatics, 25, 736-742.

Powell JR, Monaghan MT, Öpik M, Rilling MC. (2011) Evolutionary criteria outperform operational approaches in producing ecologically relevant fungal species. Molecular Ecology, 20, 655-666.

Prosser JI. (2010) Replicate or lie. Environmental Microbiology, 12, 1806-1810.

Quince C, Lanzén A, Curtis TP, Davenport RJ, Hall N, Head IM, Read LF, Sloan WT. (2009) Accurate determination of microbial diversity from 454 pyrosequencing data. Nature Methods, 6, 639-644.

Read DJ, Haselwandter K. (1981) Observations on the mycorrhizal status of some alpine plant communities. New Phytologist, 88, 341-352.

Remy W, Taylor TN, Hass H, Kerp H. (1994) Four hundred-million-year-old vesicular arbuscular mycorrhizae. PNAS, 91, 11841-11843.

Read DJ, Haselwandter K. (1981) Observations on the mycorrhizal status of some alpine plant communities. New Phytologist, 88, 341-352.

Ryberg M, Kristiansson E, Sjökvist E, Nilsson RH. (2008) An outlook on the fungal internal transcribed spacer sequences in GenBank and the introduction of a webbased tool for the exploration of fungal diversity. New Phytologist, 181, 471-477.

Schmidt SK, Sobieniak-Wiseman LC, Kageyama SA, Halloy SRP, Schadt CW. (2008) Mycorrhizal and dark-septate fungi in plant roots above 4270 meters elevation in the Andes and Rocky Mountains. Arctic, Antarctic and Alpine Research, 40, 576-583. Schoch CL, Seifert K, Huhndorf S, Robert V, Spouge JL, Levesque A, Chen W, Fungal Barcoding Consortium (2012) Nuclear ribosomal internal transcribed spacer (ITS) region as a universal DNA barcode marker for Fungi. Proceedings of the National Academy of Sciences USA, 109, 6241-6246.

Seifert KA. (2009) Progress towards DNA barcoding of fungi, Molecular ecology resources, 9, 83-89. 
Sharpton TJ, Riesenfeld SJ, Kembel SW, Ladau J, O'Dwyer JP, Green JL, Eisen JA, Pollard KS. (2011) PhylOTU: A High-Throughput Procedure Quantifies Microbial Community Diversity and Resolves Novel Taxa from Metagenomic Data. PLoS Computational Biology, 20, e1001061.

Smith SE, Read DJ. (2008) Mycorrhizal symbiosis. UK, London: Academic Press, $3^{\text {rd }}$ edition.

Stoyke G, Currah RS. (1993) Resynthesis in pure culture of a common subalpine fungusroot association using Phialocephala fortinii and Menziesia ferruginea (Ericaceae). Arctic, Antarctic and Alpine Research, 25, 189-193.

Stukenbrock EH, Rosendahl S. (2005) Distribution of dominant arbuscular mycorrhizal fungi among five plant species in undisturbed vegetation of a coastal grassland. Mycorrhiza, 15, 497-503.

Taylor AFS. (2002) Fungal diversity in ectomycorrhizal communities: sampling effort and species detection. Plant and Soil, 244, 19-28.

Taylor DL, Herriott IC, Stone KE, Mcfarland JW, Booth MG, Leigh MB. (2010) Structure and resilience of fungal communities in Alaskan boreal forest soils. Canadian Journal of Forest Research, 40, 1288-1301.

Tedersoo L, Kõljag U, Hallenberg N, Larsson K. (2003) Fine scale distribution of ectomycorrhizal fungi and roots across substrate layers including coarse woody debris in a mixed forest. New Phytologist, 159, 153-165.

Tedersoo L, Suvi T, Larsson E, Kõljag U. (2006) Diversity and community structure of ectomycorrhizal fungi in a wooded meadow. Mycologica Research, 110, 734-748.

Tedersoo L, Suvi T, Jairus T, Ostonen I, Põlm O. (2009) Revisiting ectomycorrhizal fungi of the genus Alnus: differential host specificity, diversity and determinants of the fungal community. New Phytologist, 182, 727-735.

Tedersoo L, Nilsson RH, Abarenkov K, Jairus T, Sadam A, Saar I, Bahram M, Bechem E, Chuyong G, Kóljag U. (2010) 454 pyrosequencing and Sanger sequencing of tropical mycorrhiza fungi provide similar results but reveal substantial methodological biases. New Phytologist, 188, 291-301.

Tibbett M, Sanders FE, Cairney JWG. (1998) The effect of temperature and inorganic phosphorus supply on growth and acid phosphatase production in arctic and temperate strains of ectomycorrhizal Hebeloma spp. in axenic culture. Mycological Research, 102, 129-135 
Tibbett M, Sanders FE, Cairney JWG. (1999) Long-term storage of ectomycorrhizal basidiomycetes (Hebeloma spp.) at low temperature. Journal of Basic Microbiology, 39, 381-384

Toljander JF, Artursson V, Paul LR, Jansson JK, Finlay RD. (2006) Attachment of different soil bacteria to arbuscular mycorrhizal fungal extraradical hyphae is determined by hyphal vitality and fungal species. FEMS Microbiology Letters, 254, 34-40.

Trappe JM. (1987) Phylogenetic and ecologic aspects of mycotrophy in the angiosperms from an evolutionary standpoint. In: Safir GR (ed.) Ecophysiology of VA mycorrhizal plants. CRC, Boca Raton, pp 5-25.

van Orsouw NJ, Hogers RCJ, Janssen A, Yalcin F, Snoeijers S, Verstege E, Schneiders H, van der Poel H, van Oeveren J, Verstegen H, van Eijk MJT. (2007) Complexity reduction of polymorphic sequences (CRoPSTM): A novel approach for large-scale polymorphism discovery in complex genomes. PLOS ONE, 2, e1172.

Väre H, Vestberg M, Eurola S. (1992) Mycorrhiza and root associated fungi in Spitsbergen. Mycorrhiza, 1, 93-104.

Vrålstad T. (2011) ITS, OTUs and beyond - fungal hyperdiversity calls for supplementary solutions. Molecular Ecology, 20, 2873-2875.

Walker JF, Miller OK Jr, Horton JL. (2008) Seasonal dynamics of ectomycorrhizal fungus assemblages on oak seedlings in the southeastern Appalachian Mountains. Mycorrhiza, 18, 123-132.

Walker JF, Aldrich-Wolfe L, Riffel A, Barbare H, Simpson NB, Trowbridge J, Jumpponen A. (2011) Diverse Helotiales associated with the roots of three species of Arctic Ericaceae provide no evidence for host specificity. New Phytologist, 191, 515-527.

Wang B, Qiu YL (2006) Phylogenetic distribution and evolution of mycorrhizas in land plants. Mycorrhiza, 16: 299-363.

White JR, Navlakha S, Nagarajan N, Ghodsi MR, Kingsford C, Pop M. (2010) Alignment and clustering of phylogenetic markers - implications for microbial diversity studies. BMC Bioinformatics, 11, 152.

Wintzingerode Fv, Goëbel, UB, Stackenbrandt E. (1997) Determination of microbial diversity in environmental samples: pitfalls of PCR-based rRNA analysis. FEMS Microbiology Reviews, 21, 213-229. 
Wollan AK, Bakkestuen V, Kauserud H, Gulden G, Halvorsen R. (2008) Modelling and predicting fungal distribution patterns using herbarium data. Journal of Biogeography, 35, 2298-2310.

Wilcox HE, Wang CJK. (1987) Mycorrhizal and pathological associations of dematiaceous fungi in roots of 7-month-old tree seedlings. Canadian Journal of Forest Research, 17, 884-899.

Wolfe BE, Parrent JL, Koch AM, Sikes BA, Gardes M, Klironomos JN. (2009) Spatial heterogeneity in mycorrhizal populations and communities: Scale and mechanisms. In: Mycorrhizas - Functional processes and ecological impact. Eds: Azcón-Aguilar C, Barera JM, Gianinazzi S, Gianinazzi-Pearson V. Springer-Verlag, Berlin, Heidelberg pp: 167-185.

Zinger L, Gobet A, Pommier T (2009) Two decades of describing the unseen majority of aquatic microbial diversity. Molecular Ecology, 21, 1878-1896. 



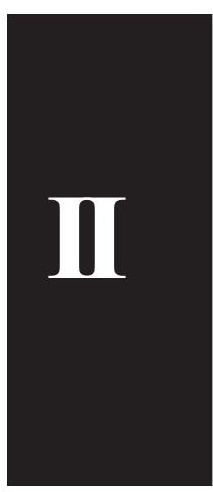





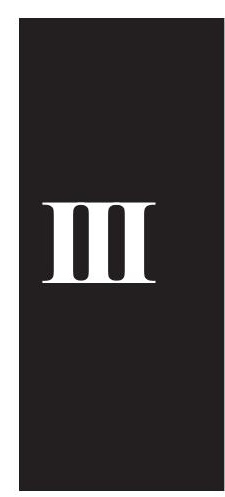





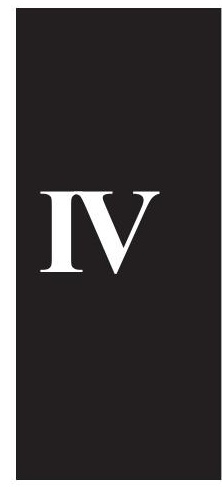



